\begin{abstract}
Motivation plays a critical role in human behavior and is particularly important during college, where a single class can make or break an academic career. The longitudinal research on expectancies for success and utility value primarily focuses on prediction or change over many years, rather than change over a short period of time. However, a single class in college can often be the difference between getting a degree or not. To better understand how motivation progresses in the short-term, we examined changes in expectancy and utility value simultaneously during a single college class. Both constructs declined during the class and showed significant variability across individuals. In addition, change in expectancy was strongly correlated with change in utility value, and the expectancy slope estimates were significant predictors of continuing interest. We discuss the need for a better understanding of short-term dynamic relationships between expectancies, utility value, and outcomes.
\end{abstract}

Keywords: Academic Achievement; Educational Psychology; Longitudinal Methodology; Motivation; Structural Equation Modeling; Dual-process Models 


\section{Short-term Motivation Trajectories: A Parallel Process Model of Expectancy-Value}

Short-term events can have lasting consequences in education. In college, a single class can be the difference between getting a degree or not (Goudas \& Boylan, 2012). For example, gatekeeper courses (i.e., foundational courses that are necessary for completion of a degree, Atanda, 1999) can single-handedly stall educational progress rather than enhance it. Negative experiences may prevent students from graduating at all (Bailey, Jeong, \& Cho, 2010; Silva \& White, 2013). Alternatively, positive experiences may lead to greater likelihood of pursuing a particular domain (Harackiewicz, Barron, Tauer, \& Elliot, 2002) or career (Pike \& Dunne, 2011). Given the positive effects that degree attainment can have on life outcomes (Bureau of Labor Statistics, 2015), it is necessary to understand the short-term dynamic processes that lead to academic success or failure. In the current study, we approach these dynamic processes from a motivational perspective by building on prior educational research.

Motivation is a critical predictor of academic achievement and engagement, particularly in higher education (Lazowski \& Hulleman, 2016; Robbins et al., 2004). As a result, it is paramount that we have an understanding of how motivation changes over short periods of time, such as over the duration of a single class. Expectancy-value models of motivation have been influential for understanding motivation in educational settings (e.g., Eccles et al., 1983). However, the bulk of expectancy-value motivation research that incorporates longitudinal designs within the educational context focuses on long-term change with yearly time points (Wigfield \& Eccles, 2002). Existing research indicates that expectancies and values decline steadily over the academic career (Jacobs, Lanza, Osgood, Eccles, \& Wigfield, 2002; MusuGillette, Wigfield, Harring, \& Eccles, 2015). However, it is less clear how that change occurs and what factors influence it in the interim. The majority of research also examines the relation 
between expectancy and value at a single time point, rather than how the constructs change in tandem with one another. Finally, research indicates that expectancy-value motivation is influenced by prior achievement from year to year (Eccles et al., 1983), yet it is unclear how motivation change relates to proximal outcomes of an interim goal (e.g., passing a single class). The current paper extends the literature by testing a process model of expectancy and value that incorporates a short-term timescale and allows for a more complete picture of the dynamics between motivation and achievement. In the current study, we constrain our discussion to the utility value component of as several studies demonstrate that it can be leveraged to improve academic outcomes such as GPA and interest (Brown, Smith, Thoman, Allen, \& Muragishi, 2015; Hulleman, Godes, Hendricks, \& Harackiewicz, 2010; Hulleman \& Harackiewicz, 2009).

\section{A Brief Overview of Expectancy-value Models}

Expectancy-value models of motivation were developed in social psychology (Atkinson, 1964; Lewin, Dembo, Festinger, \& Sears, 1944) and business management fields (Vroom, 1964) and later adapted to education (Eccles et al., 1983). According to Eccles' (1983) expectancyvalue model of achievement motivation, the most proximal determinants of achievement behavior are expectancies for success and subjective task values, including utility value. Expectancy refers to individuals' confidence in their ability to succeed at a task, and comprises effort and ability beliefs (Eccles et al., 1983). Generally, findings indicate that expectancy is most strongly related to academic achievement, including grades, course taking, activity participation, academic standing, and later expectancy (e.g., Durik, Vida, \& Eccles, 2006; Eccles, Vida, \& Barber, 2004; Hulleman, Kosovich, Barron, \& Daniel, 2016; Simpkins, DavisKean, \& Eccles, 2006). Value refers to the importance, usefulness, or enjoyment an individual associates with success on a task. It is comprised of four components (Eccles \& Wigfield, 1995): 
attainment value (the importance of the task to one's self), intrinsic value (the interest or enjoyment gained from the task), utility value (the usefulness of a task to one's goals), and cost (sacrifices or negative emotions related to the task).

Expectancies and value are positively correlated (Wigfield \& Eccles, 2000), with the magnitude of the relation ranging from small (Finney \& Schraw, 2003) to large (Papaioannou, Marsh, \& Theodorakis, 2004) depending on temporal proximity, domain overlap, and group characteristics (e.g., Kosovich, Hulleman, Barron, \& Getty, 2015). Expectancy, value, the context, and the student experience inform each other (Perez, Cromley, \& Kaplan, 2014) and students’ performance (Flake, Barron, Hulleman, McCoach, \& Welsh, 2015) as time progresses.

\subsection{The Importance of Interest in the Expectancy-Value Model}

The expectancy-value model (Eccles et al., 1983) accounts for achievement behaviors and choices, and also describes many factors that lead to lasting motivation in the form of interest. Interest refers to a psychological state that can develop into an enduring predisposition to re-engage with a particular task, topic, or content (Hidi \& Renninger, 2006). Interest is an important aspect of the achievement experience that is influenced by components of the expectancy-value model (Eccles et al., 1983; Hidi \& Renninger, 2006). To understand how expectancies and utility value relate to interest, it is helpful to compare and contrast utility value and interest. For example, Hidi and Renninger's (2006) four-phase model of interest development notes that interest is more likely to be maintained (i.e., Phase 2) if the topic or task is perceived as meaningful or useful. At the same time, expectancy pervades every level of interest development and can theoretically enhance or undermine interest (Eccles, Fredricks, \& Epstein, 2015). Thus, interest should be positively correlated with expectancy and utility value trajectories. Individuals with higher expectancy-value slopes should also report higher interest. 
Interest is also a powerful predictor of individuals' persistence and career choices. For example, Harackiewicz, Barron, Tauer, and Elliot (2002) found that interest in psychology during freshman year is a stronger predictor of college major six years later than GPA or prior performance. Qualitative research on scientists' recollections of their career paths also invokes interest as a major drive of decisions (Pike \& Dunne, 2011). Given the propensity for expectancy-value constructs to lead to greater continuing interest in a particular domain (Hulleman et al., 2010; Hulleman \& Harackiewicz, 2009), interest is an important construct to consider in relation to expectancy and utility value growth. However, the lack of information on short-term expectancy and utility value change makes it difficult to know how the two constructs relate to subsequent interest.

\subsection{Motivation Development and Conceptualizing Trajectories}

The seminal work on expectancy-value motivation in education focused on motivation development. Research in this area has since emphasized development with longitudinal methodologies. Early research demonstrated many of the factors that contribute to students' expectancy and value at a given point in time. For example, Eccles and colleagues (Eccles et al., 1983) used path models to examine predictors of expectancy and value as well as their ability to predict intentions for further course-taking. Later research (Simpkins et al., 2006) also examined reciprocal relationships between expectancy, value, and grades. In both early and later studies, researchers also examined the change in motivation over the academic career (e.g., Eccles et al., 1983; Jacobs et al., 2002). Generally speaking, expectancy-value motivation and similar constructs declines over the long-term (Durik et al., 2006; Eccles et al., 1983; Marchand \& Gutierrez, 2016; Perez et al., 2014; Ren, 2000); whether this downward trajectory is a consistent decline or not in the short-term is unclear. 
Though there is a history of longitudinal work in this area, the existing research may not extend to short time intervals. One problem is the tendency towards predicting expectancy-value constructs or using expectancy-value constructs to predict outcomes with single time point or pre-post designs (Durik et al., 2006; Eccles et al., 1983; Gillet, Berjot, Vallerand, \& Amoura, 2012; Jacobs et al., 2002; Simpkins et al., 2006; Ullrich-French \& Cox, 2014). The limitation of prediction designs is that the models focus on differences between individuals (i.e., interindividual change), rather than construct change within individuals (i.e., intra-individual change). Even studies that do calculate pre-post differences between two time points do not necessarily describe the constructs' change, as some researchers argue that true change requires at least three time points to be effectively modeled (e.g., McArdle, 2009). Of the existing research that does include three or more time points, the focus has been on long-term change over several years, rather than storm-term change (Bandura \& Schunk, 1981; Chularut \& DeBacker, 2004; Hanus \& Fox, 2015; Hidi, Berndorff, \& Ainley, 2002; Luzzo, Hasper, Albert, Bibby, \& Martinelli, 1999; Moely, McFarland, Miron, Mercer, \& Ilustre, 2002). These obstacles highlight the gap between existing longitudinal research and the current study. Although existing research findings do not necessarily extend from the long-term to the short-term, the underlying methods can be adopted relatively easily.

There are many methods available to understand motivation processes in the short-term, and different methods can answer different research questions. The number of methods available for researchers to assess change also increases with the number of data points collected. Two common approaches to assesses change with such data are repeated measures ANOVA (e.g., Field, 2013) and latent growth modeling (e.g., Duncan, Duncan, \& Strycker, 2013). Both approaches can produce estimates of the intra-individual change by capturing differences over 
time in terms or rates of change. However, latent growth modeling is being used more frequently and offers numerous advantages as a more flexible framework. This flexibility can accommodate different functional forms of change (e.g., cubic) and be easily expanded to include proximal and distal outcomes.

Frameworks such as ANOVA or path analysis conceptualize change as a series of meandifference tests or as a series of chronologically ordered predictive models. With latent growth modeling the available data are used to construct a trajectory of the construct(s). The estimation of growth parameters such as the starting point (i.e., intercept) and how the construct changes over time (i.e., slope) allows researchers to extrapolate the constructs' progression (Chou, Bentler, \& Pentz, 1998; Raudenbush \& Bryk, 2002). Such models convey a more developmental picture of the constructs under consideration. These growth models also allow researchers to consider inter-individual change by estimating the variance of individual trajectories. As such, growth modeling can illuminate how experiences or characteristics are related to construct development (Raudenbush \& Bryk, 2002) rather than test if prior experiences (e.g., prior performance, parental attitudes) explain variation in expectancy-value at a single point in time,.

Although studies that utilize growth curve modeling to understand short-term changes in expectancy and value are rare, there are other applications of growth curves that display the potential of the models to answer new and different kinds of research questions. For example, several studies have found that over the long term, expectancy and value tend to decrease on average, but the rate of change varies across people (Chouinard \& Roy, 2008; Fredricks \& Eccles, 2002; Jacobs et al., 2002). Further, Fredricks and Eccles (2002) incorporated predictors into their models to explain the variability in trajectories and found that when parents' have positive perceptions of their children's ability, the decline of students' ability beliefs is less 
extreme. In another example, Archambault, Eccles, and Vida (2010) found that different trajectory patterns characterized different groups of students by combining growth curve modeling with mixture modeling (Muthen \& Muthen, 2000).

In the current study, we utilize parallel process models within the latent growth curve framework, which allow for capturing growth in multiple constructs simultaneously (Byrne, 2012; Muthén \& Muthén, 2012). The added benefit of parallel process models (also referred to as simultaneous growth models) is that researchers can assess the covariance between intercepts and slopes within and across constructs. For example, researchers could test if expectancy and utility value change is positively related, or if a person's baseline expectancy is related to how their utility value changes. Given that expectancy and value are only moderately correlated at any time point, how one construct fluctuates during a semester may be related or unrelated to how the other fluctuates. Only a few studies examine expectancy-value change through the growth-modeling perspective (Archambault et al., 2010; Chouinard \& Roy, 2008; Fredricks \& Eccles, 2002; Jacobs et al., 2002) and we know of no previous studies explicitly investigating if expectancy change corresponded with utility value change in the short-term.

\subsection{The Current Study}

The current study was designed to extend research on short-term expectancy and utility value change in an introductory psychology classroom. Although previous literature on expectancy-value change may shed some light on what we would expect to see in the short-term, we recognize that introductory and gatekeeper courses are likely to be novel to students. As a result, many of the existing theoretical explanations used to justify motivational trends may not apply. For example, observed changes over time may be larger in the current study because students are learning about the material for the first time and have fewer prior experiences with 
the subject. College students are also more likely to be concerned with degree completion as well as job prospects than younger students. In recognition of these gaps in the research literature, we seek to answer three research questions:

(1) What are initial levels of expectancy and utility value in a college class, how do they change over the course of the class, and is there significant variability in these trajectories across participants? Based Eccles' expectancy-value model as well as prior empirical research, we hypothesize intra-individual expectancy and utility value will start out relatively high on average and decline over time. On an inter-individual level, we hypothesize that there will be substantial variability in growth among individual students - that is, some students will do well in the course and learn that it is related to their goals and interests, whereas other students will do more poorly and decline in motivation.

(2) If there is variability in how expectancy and utility value change within a semester, how is change in in the two constructs are related? We hypothesize that expectancy and utility value change will show similar patterns of change. Due to the high-stakes nature of introductory college courses (e.g., they are often required for graduation, they may be gatekeepers to specific majors), we expect a moderate relationship between the two constructs as students either develop a greater appreciation for the domain or choose to pursue other domains in which they've experienced greater success.

(3) What are the relationships between changes in expectancy and utility value and student outcomes (e.g., performance and interest) during the course of a semester? Exam scores are likely a major driver of shifts in student motivation at the college level because poor performance is not likely to encourage continued pursuit of the topic. Thus, we would expect exam scores to predict expectancy trajectories and utility value trajectories as students gain 
familiarity with the material. Similarly, we would expect expectancy and utility value trajectories to be related to whether or not students intend to pursue the topic in future course (i.e., continuing interest). Though we had limited access to demographic information in these data, we also included gender as a covariate, which is consistent with prior research.

\section{Method}

\subsection{Participants \& Procedures}

Participants $(\mathrm{N}=389 ; 51 \%$ female $)$ were enrolled in an introductory psychology course at a large, mid-western public university. Ethnicity and age information was not collected for individual students; however, the college population was 74.2\% White, 5.4\% Asian American, 2.9\% African American, 3.3\% Latino, 8.9\% international, and 5.3\% other ${ }^{1}$. The class was primarily first year students $\left(\mathrm{M}_{\mathrm{age}}=18.1\right.$ years old $)$. All students in the class were eligible to participate.

Students provided responses for expectancy and utility value measures at three time points within a 15-week semester: week 3 (Time 1), week 9 (Time 2), and week 14 (Time 3). These time points were spaced to be far enough apart to capture change and to cohere with the course and exam schedule. Questionnaires were filled out by students in class and their responses were entered by researchers.

\subsection{Missing Data}

Missing data were present during each wave of collection $(\mathrm{M}=14 \%)$. Wave one was missing approximately $24 \%$ of registered students, wave two was missing approximately $39 \%$ of students, and wave three was missing approximately $40 \%$ of students. Typically, students who were missing one measure were also missing the other measure within any give wave of data collection (e.g., they were not in class the day of the data collection). The correlation between

\footnotetext{
${ }^{1}$ Demographic information was obtained from the institutions' offices of institutional research and registrar.
} 
expectancy missingness and utility value missingness was high at wave one $(r=.97, \mathrm{n}=389)$, wave two $(r=1.00, \mathrm{n}=389)$, and wave three $(r=.98, \mathrm{n}=389)$ suggesting that differences in missing data were uncommon within each wave ${ }^{2}$. However, all exam scores were correlated with missingness in each wave. For example, exam one was correlated with missing utility value at wave one $(r=-.23 ; \mathrm{n}=358)$, wave two $(r=-.33, \mathrm{n}=358)$, and wave three $(r=-.40, \mathrm{n}=358)$. Similarly, measures of motivation were highly correlated with each other across time. We used full information maximum likelihood (FIML) to account for missing data, and exam scores and gender were used in the unconditional model as auxiliary variables (Enders, 2010). The presence of exam scores and repeated measures can reduce bias in the estimates due to missingness; however it is impossible to ensure that bias is completely removed.

\subsection{Measures}

\subsubsection{Expectancy and utility value.}

Items for this study were adapted from Eccles and colleagues (Eccles et al., 1983) and worded to capture students' levels of general expectancy (5 items; $\bar{\alpha}=.88$; e.g., "I expect to do well in this class") and utility value in the class ( 3 items; $\bar{\alpha}=.87$; "What I am learning in this class is relevant to my life."). Students indicated how true they felt the items to be on a seven point scale ranging from 1 ("Not at all True") to 7 ("Very True") scale. Previous work with these scales has indicated that their scores have adequate psychometric properties (Eccles \& Wigfield, 1995). Each subscale was averaged to create a final composite score and reliability coefficients for each wave are presented in Table 1.

\subsubsection{Continuing interest.}

Students' self-reported continuing interest was adapted from Hulleman and colleagues (Hulleman et al., 2010). Continuing interest was collected during waves one and three. The 4- 
item measure ( $\bar{\alpha}=.89$; e.g., "I am interested in majoring in psychology.") used the same response scale as the expectancy and utility value items. Individual item responses were averaged to create a final composite score.

\subsubsection{Exam scores.}

Students completed their first, second, third, and fourth exams in class during the fourth, eighth, twelfth, and sixteenth weeks of class, respectively. The scores were weighted equally in the course. Each exam was instructor-designed over several semesters, was multiple-choice, and was machine-scored with a maximum score of 60 . Student scores were generated by summing the number of correct responses. Item-level data were unavailable for exam scores, meaning that it was not possible to calculate reliability indices for exam scores. However, the fact that exam scores here strongly and positively correlated over time, and that exam scores were positively correlated with measures of expectancies at each time point at expected magnitudes provides secondary evidence of score reliability (AERA, APA, \& NCME, 2014). Furthermore, all exams were a part of an accredited university course that contributed to students' permanent academic GPA. As a result, these are meaningful representations of achievement in this college class.

\subsection{Analytic Procedures}

We used latent growth curve analyses in a structural equation modeling (SEM) framework, executed in Mplus version 7.2. SEM provided a flexible analytical framework for modeling students' change over time on two constructs simultaneously. We were also able to model the relationships between change and other variables of interest. Models were estimated using full information maximum likelihood estimation (FIML) to make use of all available data.

\section{Results}

\subsection{Descriptive Statistics}


Table 1 contains descriptive statistics and correlations. Generally speaking, both expectancy and utility value displayed decreasing trajectories over time. For example, expectancy began relatively high and decreased over time: $\mathrm{M}_{\mathrm{T} 1}=5.46, \mathrm{SD}=0.83 ; \mathrm{M}_{\mathrm{T} 2}=4.92$, $\mathrm{SD}=1.16 ; \mathrm{M}_{\mathrm{T} 3}=4.68, \mathrm{SD}=1.34$. Utility value followed a similar trajectory: $\mathrm{M}_{\mathrm{T} 1}=4.97, \mathrm{SD}=$ $1.07 ; \mathrm{M}_{\mathrm{T} 2}=4.83, \mathrm{SD}=1.12 ; \mathrm{M}_{\mathrm{T} 3}=4.76, \mathrm{SD}=1.26$. Expectancy and utility value were correlated with each other at all three time points $\left(r_{\mathrm{T} 1}=.32, r_{\mathrm{T} 2}=.42, r_{\mathrm{T} 3}=.44\right)$. In general, expectancy and exam scores became more correlated over time; a similar pattern was present between utility value over time and interest.

\subsection{Model A: Unconditional Growth Model}

\subsubsection{Model A Specification}

We began by building an unconditional parallel process model (see Figure 1), which models two separate constructs simultaneously (Byrne, 2012; Muthén \& Muthén, 2012). In addition to the discussed benefits of a typical latent growth model—parallel process models provide estimates of growth-parameter covariances. Model A captured the initial levels of expectancy and utility value at the beginning of the semester (i.e., the intercepts), the change over time (i.e., the slopes), their variances, and the relationships between the intercepts and the slopes $^{3}$. Time was coded by data collection wave ${ }^{4}$, such that the intercept represents the first wave (third week of the semester) and the slope represents the expected change as one wave passes. Model A provided a baseline comparison for later models in terms of growth parameters

\footnotetext{
${ }^{3}$ Model A has one constraint, the residual variance of expectancy at Time 3 was fixed to zero-in initial runs this variance was estimated to be negative and non-significant, causing non-positive definitive residual covariance matrix. Fixing this residual variance to zero remedied the issue with the residual covariance matrix.

${ }^{4}$ Data waves were coded as 0 (week 3), 1 (week 9) and 1.83 (week 14). We chose 1.83 rather than 2 because it more accurately accounts for the fact the time between the first two waves was 6 weeks long and the second two waves was 5 weeks (i.e., 83\%) long. We chose this coding scheme for two reasons: (1) the time between waves was rather equally spaced out, and (2) coding by smaller units (days or weeks) produced estimates in small units, which caused estimation problems for near zero variance estimates.
} 
and model fit. Statistically, expectancy and utility value are modeled as two separate, straight lines that represent motivation across multiple time points. Conceptually, however, it is more accurate to think of expectancy and utility value as two intertwined constructs that gradually change together over time. Model A answers the first research question, What are initial levels of expectancy and utility value in a college class, how do they change over the course of the class, and is there significant variability in these trajectories among participants? And research question 2, How is change in expectancy related to change in utility value?

\subsubsection{Model A Results}

The primary estimates of interest in Model A were the intercept and slope means, variances, and correlations between the intercepts and slopes. The growth parameter estimates provided are unstandardized and the correlations provided are standardized for ease of interpretation (see Table 2). The expectancy and utility value intercepts were statistically significantly correlated, $r=.52, p<.01$, meaning that expectancy and utility value were strongly related at Time 1. Both expectancy slope, $-0.31, p<.01,99 \%$ CI $[-.40,-.22]$ and the utility value slope $-0.09, p<.01,99 \%$ CI $[-.17,-.003]$ were negative and statistically significant. In other words, expectancy-value motivation decreased over the course of the semester on average. The expectancy slope variability was also statistically significant, $\mathrm{SD}=.51, p<.01$, meaning that individual students displayed varying expectancy trajectories. The 95\% plausible values range describes the range of potential expectancy slopes in the population and was from -1.47 to 0.79 , with some trajectories being negative and some being positive. In contrast, the utility value slope variability was not statistically significant, $\mathrm{SD}=.28, p=.31^{5}$; the decline in utility value was consistent across students. Relatedly the $95 \%$ plausible values range was from -0.69 to 0.49 .

\footnotetext{
${ }^{5}$ The results of Model A were conflicting because the variance slope, while non-significant statistically, improved model fit and was correlated with other estimates in the model. As a result, we elected to retain the utility value slope variance despite its lack of statistical significance.
} 
Interestingly, the slopes for expectancy and utility value were strongly and significantly correlated, $r=.83, p<.01$ (see Figure 2), meaning that individuals with positive expectancy slopes also likely had positive utility value slopes and individuals with negative expectancy slopes likely also had negative utility value slopes. Importantly, fit indices suggested that Model A accurately represented the data $\chi 2(8)=24.70, p<.01 ; \mathrm{RMSEA}=.08 ; \mathrm{CFI}=.98, \mathrm{TLI}=.95$.

\subsection{Model B: Conditional Growth Model with Outcomes and Gender}

\subsubsection{Model B Specification.}

Model B was developed to test the parallel growth of expectancy and utility value in the context of major factors and experiences in the learning environment (see Figure 3). To do so, we introduced three common factors that play a role in students' motivational developmentgender, interest, and achievement. Because gender differences have historically been found in motivation and educational outcomes, we included it as a predictor in the model. As coursework is largely focused on achievement outcomes in the form of exams, we included four exams from the semester in the model. The exams were administered between expectancy-value data collection and so provided an opportunity to study the dynamic relationship between expectancyvalue growth and performance feedback. Whereas the first three exams were modeled concurrently with the growth process, the fourth exam was modeled as an outcome. Because the expectancy-value model posits that expectancies are partially determined by prior achievement, we modeled the first three exam scores as covariates. Theoretically, exam performance should lead to changes in expectancy. However, the correlational nature of the study precludes any causal inference. We suggest that path coefficients represent controlling of motivational trajectories and points of student achievement, rather than causal effects of one on the other. 
Because the exams were on discrete content, we included them as an autoregressive component of the model rather than as an additional growth trajectory. The autoregressive approach is more appropriate than a growth model in this case because the exams would not effectively measure performance growth. Scoring lower on Exam 2 than on Exam 1 would not indicate that one's psychology knowledge decreased. However, we would expect students who perform better than other students on Exam 1 to also perform better than other students on Exam 2. This difference highlights a contrast between autoregressive and growth modeling paradigms. The most accurate interpretation of the slope estimates for expectancy and utility value in this model are as conditional estimates (e.g., conditional after controlling for other factors in the model such as exam scores).

Finally, students' continuing interest was included as an additional important educational outcome near the end of the semester-baseline interest was also included as a covariate. Model $\mathrm{B}$ answers the third, What are the dynamic relationships between motivation change and our primary outcomes (interest and exam performance) during the course of a semester?

\subsubsection{Model B Results.}

Figure 4 displays information regarding significant paths from Model B (for full model specifications, see Table S4 in the supplemental materials). The primary relationships of interest in Model B were the dynamics between motivation change and achievement, the effects of gender on motivation growth (binary variable where men $=1$ and women $=0$ ), and the effects of motivation growth on interest and fourth exam scores. First, we found that there was a gender effect on initial expectancy, $b=-0.22, \mathrm{SE}=0.04$, suggesting that women in the psychology class were likely to report lower expectancy than men. Gender had no other statistically significant relationships with variables in the model. 
Expectancy intercepts were predictive of Exam 1 scores, $b=.35, \mathrm{SE}=0.07$, suggesting that students' confidence in their ability to succeed in a class early in the semester is indicative of their early course performance- - however, their early expectancy showed no direct effects on later exam scores. Utility value intercepts were unrelated to performance at any point.

Exam 1 performance directly predicted later exam performance but was not related to expectancy change, $b=0.01, \mathrm{SE}=0.01$, or utility value change $b<-0.01, \mathrm{SE}=0.01$. In contrast, Exam 2, $b=0.02, \mathrm{SE}=0.01$, and Exam 3, $b=0.02, \mathrm{SE}=0.01$, were related to expectancy change. Although these coefficients appear small, the $\mathrm{R}^{2}$ value for expectancy slopes is quite large, showing that $52 \%$ of the variance is explained. Given that only Exam 2 and Exam 3 are significantly related to the expectancy slopes, this suggests that they share the majority of explained variance in the expectancy slopes. This means that individuals who did well on exams were more likely to have less rapidly declining motivational trajectories, and conversely, those who did poorly on these exams were likely to have more rapidly declining trajectories. Interestingly, utility value slopes related to Exam 3 scores, $b=0.01, \mathrm{SE}=0.01$, but were unrelated to any other achievement measures in the study.

Finally, we examined the effects of the motivation growth on our primary outcomes, long-term interest and fourth exam performance. Interest was predicted by utility value intercepts, $b=0.35, \mathrm{SE}=0.17$, and expectancy slopes, $b=1.03, \mathrm{SE}=0.48$, however, it was unrelated to utility value slopes, $b=0.30, \mathrm{SE}=0.76$. These results suggest that students' expectancy trajectories are indicative of their late-semester interest. Fourth exam was only predicted by other exam scores, suggesting that any relationships to motivation, if they exist, are either accounted for by prior achievement, or are indirect.

\subsection{Discussion}


The goals of the current research were to understand short-term changes in college students' motivation towards an introductory psychology class. Our results indicate that motivation meaningfully changes during the semester, and is related to and predictive of important educational factors. We first discuss our general findings about change and then the theoretical implications of the results, particularly as they relate to the dynamics of motivation.

\subsection{Expectancy and Utility Value Change}

The results of the current study correspond with trends found in the limited number of short-term (Moely et al., 2002; Perez et al., 2014) and long-term studies on motivation change (Jacobs et al., 2002). We found that both expectancy and utility value were relatively high at the beginning of the semester and both declined over time. We observed greater variance in expectancy slopes than utility value slopes. Despite the relative uniformity of utility value change over time, the correlation between expectancy and utility value slopes was statistically significant and large. Given that change in expectancy is predictive of interest, it is plausible that expectancy is the major interest leverage point in this natural education setting. The casual relationship between expectancy and utility value change is ambiguous in these data, as both were collected at the same time. Investigating a causal relationship between expectancy change and utility value change is an important area for future research; as such a link would greatly inform education and intervention practice. We hypothesize that expectancy and utility value operate through recursive processes and ultimately lead to increased or decreased performance, but because these data are correlational, future research his needed to investigate our hypothesis.

The lack of variation if utility value slopes was puzzling and yields at least two potential hypotheses that merit further investigation. Information in the classroom that can augment expectancies is abundant and typically explicit across diverse learning environments, as students 
get grades from exams and assignments. That feedback is critically linked to students expectancies across time (Bandura \& Schunk, 1981). Utility value, however, may be less explicitly addressed in the classroom. This could result in students' entering the classroom with certain level of utility value and maintaining those attitudes over time. Another hypothesis is that even when utility value is addressed in the classroom, it does not necessarily cause students' to change their attitudes. For example, a review of research on relating math to real life suggested that faculty and students often have different interpretations of what it means to make coursework relevant (Carraher \& Schliemann, 2002). Because we did not measure the amount of utility value messaging sent by teachers or received by students, we can only speculate as to the reasons behind the stability of utility value. Replicating and further exploring this finding could be the subject of future research.

\subsection{Dynamics of Motivation Change and Theoretical Implications}

This study was meant to examine motivation dynamics in achievement at a more finegrained level than most prior research. In considering these motivational dynamics, two major threads emerged from our results: (1) the positive relationship between initial utility value, expectancy change, and continuing interest and (2) the positive relationship between expectancy change and exam scores.

The current study supports prior research demonstrating a strong link between interest, utility value (Shechter, Durik, Miyamoto, \& Harackiewicz, 2011) and expectancy (Hidi \& Renninger, 2006). First, we found a positive link between initial utility value and end-ofsemester interest even after controlling for baseline interest. This finding is consistent with Hidi and Renninger's (2006) model of interest development that suggests individuals who perceive meaningfulness will develop more enduring interest. Second, continuing interest was also 
predicted by expectancy slopes, suggesting that self-perceptions of ability increase along with the desire to re-engage with the domain. Individuals with more negative expectancy trajectories were also more likely to report lower continuing interest at the end of the semester whereas the degree of utility value change reported by students was unrelated to interest. This is also consistent with Hidi and Renninger's (2006) model of interest development that suggests interest continually requires external support at all stages. In the case of the current study, positive expectancy growth may correspond with positive external support whereas negative expectancy change may reduce interest. These two findings suggest differentiated, independent relationships with interest (although the lack of utility value slope variability may be masking a relationship).The results of this study are consistent with theoretical discussions linking expectancy-value models with interest (Eccles et al., 2015; Wigfield \& Cambria, 2010) as well as Hidi and Renninger's theorized dynamics of interest development. These sorts of dynamic processes can only be captured when constructs are modeled together, and the results highlight the benefits of parallel process and flexible latent variable models. An important extension beyond this work, however, is that these processes are happening dynamically over a very short period of time, a few months.

The second point to consider is that exam performance as a whole explained about half of the variation in expectancy change (albeit with small unique effects), but expectancy change does not predict later exam performance. It may be that the correlations between expectancies at a given time point and fourth exams are simply proxies for recent achievement. In other words, measuring proximal achievement may reduce the predictive relationship expectancies on achievement outcomes. What does this mean for researchers? Including proximal achievement data may be a key to understanding expectancy effects, but expectancy is a strong proxy for prior 
achievement. Theoretically, the results are also interesting. The fact that exam scores predict expectancy change seems to follow logic and past research — individuals who perform worse should lose confidence that they will succeed. However, that expectancy slopes are unrelated to fourth exam scores contrasts the idea that expectancies actually influence performance. Given this fact, further research is needed on the early achievement motivation dynamics during a semester, particularly in terms of the causal direction (if any) of these relationships. The first couple of weeks of a semester may be some of the most critical in terms of motivation and subsequent achievement.

\subsection{Limitations and Future Directions}

There are notable limitations that constrain the conclusions drawn from this study and direct our discussion. First, as we do not have access to the content of the exam, it is possible that these findings do not extend to all psychology courses. Even if they are representative of college psychology in general, it is unlikely that they are generalizable to other academic domains. As described by Jacobs and colleagues (Jacobs et al., 2002), motivational trajectories depend on the domain in which they are contextualized - there is no reason to expect otherwise in the current study. Future research would benefit from conducting such a study with the same students in multiple courses and contexts. Not only would such a study illuminate differences in motivation trajectories in different domains, it would allow researchers to examine common motivation change that may reach across domains.

Second, motivational decline appears to be generally consistent across ages, domains, and contexts in the prior literature as well as the current study. In spite of that mean-level uniformity, there is evidence of individual variation in motivational trajectories (Jacobs et al., 2002), with some students in the current study showing upwards rather than downwards 
trajectories. The current study only includes one measure of individual characteristics (i.e., gender) and no measures of students' contextual experiences. In the case of gender, men appeared to display higher initial expectancy than women-however it is difficult to ascertain whether or not such a difference is to be expected. For example, psychology tends to have more women in undergraduate course whereas men are heavily overrepresented in the field. In either case, students' individual group membership could result in higher expectancies that the other group. At the same time, psychology is less familiar at the introductory level than other fields such as mathematics or language arts and there may no differences in motivation at all. Thus, any pattern of results could feasibly be hypothesized. In order to better understand this gender discrepancy, as well as why individuals' motivation declines in this particular setting, future research would benefit from assessing students from many classrooms at once. Such an undertaking could test which teaching practices or institution-level policies might explain variation in trajectories, as well as other ways students might differentiate themselves within a class.

Third, these findings are restricted to the growth of expectancy and utility value, rather than all types of value. Thus, the generalizability of these findings only applies to expectancy and utility value. The other components of Eccles' model (intrinsic value, attainment value, and cost) are empirically and theoretically distinct constructs (Eccles et al., 1983; Flake, Barron, Hulleman, McCoach, \& Welsh, 2015; Gaspard et al., 2015), and may follow different trajectories during the course of an individual semester. For example, prior research (Hulleman \& Harackiewicz, 2009) has demonstrated that utility value is uniquely related to expectancies. It may be that case that expectancy and value change in our study was more highly correlated than it would be otherwise because of our focus on utility value. Future research would benefit by 
investigating the relationships between the change estimates of different motivation components. Particularly, it is unknown how change in other types of value and change in cost change is related to expectancy or interest change. This would provide a more detailed statistical model that incorporates the dynamic processes theorized by motivational researchers (Eccles et al., 1983; Hidi \& Renninger, 2006).

Fourth, the generalizability of this study is limited to relatively high achieving students. These data were collected in a research intensive university with a selective admissions process. Further, these students are relatively homogenous in their race, age, and other demographic factors. With a more diverse sample we may see a different pattern of variability of these constructs, and accordingly, a different set of predictive relationships. As such, studies of shortterm change in different populations of students maybe particularly insightful for understanding the experience and outcomes of different types of students in higher education. Learning processes in gatekeeper courses may be particularly informed by motivation.

Finally, only three time points were present in the current study, meaning that we were unable to model non-linear growth or incorporate time-varying covariates. It is possible that with more time points we would observe a quadratic or cubic growth trajectory. Further we may be able to better understand performance influences motivation alongside time. Understanding the ebb and flow of student motivation during the short-term would facilitate the generation of more specific and detailed theoretical models, providing an avenue to test them. These advances expand our knowledge of the complex nature and dynamic processes of motivation, which would allow us to inform intervention research and education practice. Ultimately, we may be able to use that knowledge to catalyze recursive processes and set students on positive long term trajectories, particularly in gatekeeper courses, which are required for success in college. The 
current study showcases what we can learn by re-focusing some research questions on short-term motivation change. Furthermore, the limitations serve to strengthen the call for more research on this topic - the current study only scratches the surface. 


\section{References}

AERA, APA, \& NCME. (2014). Standards for Educational and Psychological Testing. Washington, DC: American Educational Research Association.

Archambault, I., Eccles, J. S., \& Vida, M. N. (2010). Ability self-concepts and subjective value in literacy: Joint trajectories from grades 1 through 12. Journal of Educational Psychology, 102(4), 804-816. http://doi.org/10.1037/a0021075

Atanda, R. (1999). Do gatekeeper courses expand educational options? Educational Statistics Quarterly, 1(1), 33-38.

Atkinson, J. W. (1964). An introduction to motivation. Princeton, NJ: D. Van Nostrand Company, Inc.

Bailey, T., Jeong, D. W., \& Cho, S. W. (2010). Referral, enrollment, and completion in developmental education sequences in community colleges. Economics of Education Review, 29(2), 255-270. http://doi.org/10.1016/j.econedurev.2009.09.002

Bandura, A., \& Schunk, D. H. (1981). Cultivating competence, self-efficacy, and intrinsic interest through proximal self-motivation. Journal of Personality and Social Psychology, 41(3), 586-598. http://doi.org/10.1037/0022-3514.41.3.586

Brown, E. R., Smith, J. L., Thoman, D. B., Allen, J. M., \& Muragishi, G. (2015). From bench to bedside: A communal utility value intervention to enhance students' biomedical science motivation. Journal of Educational Psychology, 107(4), 1116-1135. http://doi.org/10.1037/edu0000033

Bureau of Labor Statistics. (2015). Employment Projections. Retrieved March 9, 2015, from http://www.bls.gov/emp/ep_chart_001.htm

Byrne, B. M. (2012). Structural equation modeling with Mplus : basic concepts, applications, 
and programming. Multivariate applications series.

Carraher, D. W., \& Schliemann, A. D. (2002). Chapter 8: Is everyday mathematics truly relevant to Mmathematics. Journal for Research in Mathematics Education. Monograph, 11(May), 131. http://doi.org/10.2307/749968

Chou, C., Bentler, P. M., \& Pentz, M. A. (1998). Comparisons of two statistical approaches to study growth curves: The multilevel model and the latent curve analysis. Structural Equation Modeling: A Multidisciplinary Journal, 5(3), 247-266. http://doi.org/10.1080/10705519809540104

Chouinard, R., \& Roy, N. (2008). Changes in high-school students' competence beliefs, utility value and achievement golas in mathematics. British Journal of Educational Psychology, 78, 31-50. http://doi.org/10.1348/000709907X197993

Chularut, P., \& DeBacker, T. K. (2004). The influence of concept mapping on achievement, selfregulation, and self-efficacy in students of English as a second language. Contemporary Educational Psychology, 29(3), 248-263. http://doi.org/10.1016/j.cedpsych.2003.09.001

Duncan, T. E., Duncan, S. C., \& Strycker, L. A. (2013). An introduction to latent variable growth curve modeling: Concepts, issues, and application. Routledge Academic.

Durik, A. M., Vida, M., \& Eccles, J. S. (2006). Task values and ability beliefs as predictors of high school literacy choices: A developmental analysis. Journal of Educational Psychology, 98(2), 382-393. http://doi.org/10.1037/0022-0663.98.2.382

Eccles, J. S., Adler, T., Futterman, R., Goff, S. B., Kaczala, C. M., Meece, J. L., \& Midgley, C. (1983). Expectancies, Values, and Academic Behaviors. In J. T. Spence (Ed.), Achievement and achievement motivation (pp. 75-146). San Francisco, CA: W. H. Freeman.

Eccles, J. S., Fredricks, J. A., \& Epstein, A. (2015). Understanding well-developed Interests and 
activity commitment. In K. A. Renninger \& S. Hidi (Eds.), The Power of Interest for Motivation and Engagement (pp. 315-330). Routledge.

Eccles, J. S., Vida, M. N., \& Barber, B. (2004). The relation of early adolescents' college plans and both academic ability and task-value beliefs to subsequent college enrollment. Journal of Early Adolescence, 24(1), 63-77. http://doi.org/10.1177/0272431603260919

Eccles, J. S., \& Wigfield, A. (1995). In the mind of the actor: The structure of adolescents' achievement task values and expectancy-related beliefs. Personality and Social Psychology Bulletin, 21, 215-225. http://doi.org/10.1177/0146167295213003

Enders, C. K. (2010). Maximum Likelihood Estimation. Applied Missing Data.

Field, A. (2013). Discovering statistics using IBM SPSS statistics. Sage.

Finney, S. J., \& Schraw, G. (2003). Self-efficacy beliefs in college statistics courses. Contemporary Educational Psychology. http://doi.org/10.1016/S0361-476X(02)00015-2

Flake, J. K., Barron, K. E., Hulleman, C., McCoach, B. D., \& Welsh, M. E. (2015). Measuring cost: The forgotten component of expectancy-value theory. Contemporary Educational Psychology, 41, 232-244. http://doi.org/10.1016/j.cedpsych.2015.03.002

Fredricks, J. a., \& Eccles, J. S. (2002). Children's competence and value beliefs from childhood through adolescence: Growth trajectories in two male-sex-typed domains. Developmental Psychology, 38(4), 519-533. http://doi.org/10.1037//0012-1649.38.4.519

Gaspard, H., Dicke, A., Flunger, B., Schreier, B., Häfner, I., Trautwein, U., \& Nagengast, B. (2015). More value through greater differentiation: Gender differences in value beliefs about math. Journal of Educational Psychology, 107(3), 663-677. http://doi.org/10.1037/edu0000003

Gillet, N., Berjot, S., Vallerand, R. J., \& Amoura, S. (2012). The role of autonomy support and 
motivation in the prediction of interest and dropout intentions in sport and education settings. Basic and Applied Social Psychology, 34(3), 278-286.

http://doi.org/10.1080/01973533.2012.674754

Goudas, A. M., \& Boylan, H. R. (2012). Addressing flawed research in developmental education. Journal of Developmental Education, 36(1), 2-4-13.

Hanus, M. D., \& Fox, J. (2015). Assessing the effects of gamification in the classroom: A longitudinal study on intrinsic motivation, social comparison, satisfaction, effort, and academic performance. Computers \& Education, 80, 152-161. http://doi.org/10.1016/j.compedu.2014.08.019

Harackiewicz, J. M., Barron, K. E., Tauer, J. M., \& Elliot, A. J. (2002). Predicting success in college: A longitudinal study of achievement goals and ability measures as predictors of interest and performance from freshman year through graduation. Journal of Educational Psychology, 94(3), 562-575. http://doi.org/10.1037/0022-0663.94.3.562

Hidi, S., Berndorff, D., \& Ainley, M. (2002). Children's argument writing, interest and selfefficacy: An intervention study. Learning and Instruction, 12(4), 429-446. http://doi.org/10.1016/S0959-4752(01)00009-3

Hidi, S., \& Renninger, K. A. (2006). The four-phase model of interest development. Educational Psychologist, 41(2), 111-127. http://doi.org/10.1207/s15326985ep4102_4

Hulleman, C. S., Godes, O., Hendricks, B. L., \& Harackiewicz, J. M. (2010). Enhancing interest and performance with a utility value intervention. Journal of Educational Psychology, 102(4), 880-895. http://doi.org/10.1037/a0019506

Hulleman, C. S., \& Harackiewicz, J. M. (2009). Promoting interest and performance in high school science classes. Science (New York, N.Y.), 326(5958), 1410-1412. 
http://doi.org/10.1126/science. 1177067

Hulleman, C. S., Kosovich, J. J., Barron, K. E., \& Daniel, D. B. (2016). Making connections: Replicating and extending the utility value intervention in the classroom. Journal of Educational Psychology. http://doi.org/10.1037/edu0000146

Jacobs, J. E., Lanza, S., Osgood, D. W., Eccles, J. S., \& Wigfield, A. (2002). Changes in children's self-competence and values: gender and domain differences across grades one through twelve. Child Development, 73(2), 509-527. http://doi.org/10.1111/14678624.00421

Kosovich, J. J., Hulleman, C. S., Barron, K. E., \& Getty, S. (2015). A practical measure of student motivation: Establishing validity evidence for the expectancy-value-cost scale in middle school. The Journal of Early Adolescence, 35(5-6), 790-816. http://doi.org/10.1177/0272431614556890

Lazowski, R. A., \& Hulleman, C. S. (2016). Motivation interventions in education: A metaanalytic review. Review of Educational Research, 86(2), 602-640. http://doi.org/10.3102/0034654315617832

Lewin, K., Dembo, T., Festinger, L., \& Sears, P. S. (1944). Level of aspiration. In J. M. Hunt (Ed.), Personality and the behavior disorders (pp. 333-378). New York: Ronal Press. http://doi.org/10.1037/10319-006

Luzzo, D. A., Hasper, P., Albert, K. A., Bibby, M. A., \& Martinelli, E. A. (1999). Effects of selfefficacy-enhancing interventions on the math/science self-efficacy and career interests, goals, and actions of career undecided college students. Journal of Counseling Psychology, 46(2), 233-243. http://doi.org/10.1037/0022-0167.46.2.233

Marchand, G. C., \& Gutierrez, A. P. (2016). Processes involving perceived instructional support, 
task value, and engagement in graduate education. The Journal of Experimental Education, 1-20. http://doi.org/10.1080/00220973.2015.1107522

McArdle, J. J. (2009). Latent variable modeling of differences and changes with longitudinal data. Annual Review of Psychology, 60(1), 577-605. http://doi.org/10.1146/annurev.psych.60.110707.163612

Moely, B. E., McFarland, M., Miron, D., Mercer, S., \& Ilustre, V. (2002). Changes in college students' attitudes and intentions for civic involvement as a function of service-learning experiences. Michigan Journal of Community Service Learning, 9(1), 18-26.

Musu-Gillette, L. E., Wigfield, A., Harring, J. R., \& Eccles, J. S. (2015). Trajectories of change in students' self-concepts of ability and values in math and college major choice. Educational Research and Evaluation, 21(4), 343-370. http://doi.org/10.1080/13803611.2015.1057161

Muthen, B., \& Muthen, L. K. (2000). Integrating person-centered and variable-centered analyses: Growth mixture modeling with latent trajectory classes. Alcoholism: Clinical and Experimental Research, 24(6), 882-891. http://doi.org/10.1111/j.1530-0277.2000.tb02070.x

Muthén, L., \& Muthén, B. (2012). Mplus user's guide (version 7.2). Los Angeles: Author. Retrieved from http://scholar.google.com/scholar?hl=en\&btnG=Search\&q=intitle:Mplus+user+guide\#8

Papaioannou, A., Marsh, H. W., \& Theodorakis, Y. (2004). A multilevel approach to motivational climate in physical education and sport settings: An individual or a group level construct? Journal of Sport \& Exercise Psychology, 26, 90-118.

Perez, T., Cromley, J. G., \& Kaplan, A. (2014). The role of identity development, values, and costs in college STEM retention. Journal of Educational Psychology, 106(1), 315-329. 
http://doi.org/10.1037/a0034027

Pike, A. G., \& Dunne, M. (2011). Student reflections on choosing to study science post-16. Cultural Studies of Science Education, 6(2), 485-500. http://doi.org/10.1007/s11422-0109273-7

Raudenbush, S. W., \& Bryk, A. S. (2002). Hierarchical Linear Models: Applications and Data Analysis Methods (Second). SAGE Publications, Inc.

Ren, W.-H. (2000). Library instruction and college student self-efficacy in electronic information searching. The Journal of Academic Librarianship, 26(5), 323-328. http://doi.org/10.1016/S0099-1333(00)00138-5

Robbins, S. B., Lauver, K., Le, H., Davis, D., Langley, R., \& Carlstrom, A. (2004). Do Psychosocial and Study Skill Factors Predict College Outcomes? A Meta-Analysis. Psychological Bulletin, 130(2), 261-288. http://doi.org/10.1037/0033-2909.130.2.261

Shechter, O. G., Durik, A. M., Miyamoto, Y., \& Harackiewicz, J. M. (2011). The role of utility value in achievement behavior: the importance of culture. Personality and Social Psychology Bulletin, 37(3), 303-317. http://doi.org/10.1177/0146167210396380

Silva, E., \& White, T. (2013). Pathways to improvement: Using psychological strategies to help college students master developmental math. Carnegie Foundation for the Advancement of Teaching. Retrieved from http://www.carnegiefoundation.org/sites/default/files/pathways_to_improvement.pdf

Simpkins, S. D., Davis-Kean, P. E., \& Eccles, J. S. (2006). Math and science motivation: A longitudinal examination of the links between choices and beliefs. Developmental Psychology, 42(1), 70-83. http://doi.org/10.1037/0012-1649.42.1.70

Ullrich-French, S., \& Cox, A. E. (2014). Normative and intraindividual changes in physical 
education motivation across the transition to middle school: A multilevel growth analysis. Sport, Exercise, and Performance Psychology, 3(2), 132-147. http://doi.org/10.1037/spy0000005

Vroom, V. H. (1964). Work and motivation. Classic readings in organizational behavior. New York: John Wiley \& Sons, Inc.

Wigfield, A., \& Cambria, J. (2010). Students' achievement values, goal orientations, and interest: Definitions, development, and relations to achievement outcomes. Developmental Review, 30(1), 1-35. http://doi.org/10.1016/j.dr.2009.12.001

Wigfield, A., \& Eccles, J. S. (2000). Expectancy - value theory of achievement motivation. Contemporary Educational Psychology, 25(1), 68-81. http://doi.org/10.1006/ceps.1999.1015

Wigfield, A., \& Eccles, J. S. (2002). The development of competence beliefs, expectancies for success, and achievement values from childhood through adolescence. In Development of Achievement Motivation (pp. 91-120). http://doi.org/10.1016/B978-012750053-9/50006-1 


\section{Figure Notes}

Figure 1. Model A: Unconditional Parallel Process Model. Expectancy and utility value selfreports measured at Time 1, Time 2, and Time 3 are used to calculate growth parameters (i.e., intercepts and slopes) as well as their covariances. Double-headed arrows represent covariances. Single-headed arrows represent path coefficients. Bolded, solid lines represent intercept path specifications, which are each set to 1.00 for expectancy (E1, E2, E3) and utility value (V1, V2, V3). Bolded, dashed lines represent slope path specifications which are set to $0.00,1.00$, and

\subsection{3 for}

Figure 2. Relationship between Expectancy and Utility value Slopes. Individual trajectory estimates from Expectancy Slopes (x-axis) and Utility value Slopes (y-axis) were strongly correlated in the unconditional growth model. Although the variance of utility value slopes was non-significant, it significantly co-varied with the expectancy slopes. As a result, our later models included utility value slopes as an estimated parameter.

Figure 3. Trimmed Path Model. The final trimmed model here represents the statistically significant paths that were present in Model B. Straight arrows represent regression paths. Curved, double-headed arrows represent correlations. Utility values presented are unstandardized path coefficients with standard errors displayed in parentheses. Bolded, solid lines represent intercept path specifications, which are each set to 1.00 for expectancy (E1, E2, E3) and utility value (V1, V2, V3). Bolded, dashed lines represent slope path specifications which are set to $0.00,1.00$, and 1.83 for expectancy and utility value times 1,2 , and 3 respectively. 
Table 1

Means, Standard Deviations, Reliabilities, and Correlations between Expectancy, Utility Value, Exam Scores, and Interest

\begin{tabular}{|c|c|c|c|c|c|c|c|c|c|c|c|c|c|c|c|}
\hline & $(\mathrm{N}=389)$ & $\mathrm{M}$ & $\mathrm{SD}$ & 1 & 2 & 3 & 4 & 5 & 6 & 7 & 8 & 9 & 10 & 11 & 12 \\
\hline 1 & Utility value $\mathrm{T} 1$ & 4.97 & 1.07 & .85 & & & & & & & & & & & \\
\hline 2 & Utility value $\mathrm{T} 2$ & 4.83 & 1.12 & .61 & .86 & & & & & & & & & & \\
\hline 3 & Utility value T3 & 4.76 & 1.26 & .61 & .75 & .89 & & & & & & & & & \\
\hline 4 & Expectancy T1 & 5.46 & 0.83 & .32 & .29 & .28 & .83 & & & & & & & & \\
\hline 5 & Expectancy T2 & 4.92 & 1.16 & .21 & .42 & .40 & .56 & .90 & & & & & & & \\
\hline 6 & Expectancy T3 & 4.68 & 1.34 & .16 & .35 & .44 & .48 & .84 & .92 & & & & & & \\
\hline 7 & Exam 1 & 44.85 & 8.09 & .00 & .23 & .18 & .27 & .62 & .67 & -- & & & & & \\
\hline 8 & Exam 2 & 42.22 & 8.20 & .01 & .24 & .24 & .26 & .64 & .68 & .70 & -- & & & & \\
\hline 9 & Exam 3 & 42.10 & 8.83 & -.02 & .17 & .21 & .23 & .55 & .68 & .76 & .68 & -- & & & \\
\hline 10 & Final Exam & 43.41 & 8.00 & .01 & .23 & .19 & .20 & .51 & .60 & .76 & .71 & .75 & -- & & \\
\hline 11 & Interest $\mathrm{T} 1$ & 3.47 & 1.51 & .47 & .42 & .46 & .27 & .19 & .16 & .00 & -.01 & .04 & -.00 & .87 & \\
\hline 12 & Interest $\mathrm{T} 3$ & 2.95 & 1.71 & .41 & .49 & .56 & .22 & .43 & .48 & .30 & .30 & .33 & .27 & .68 & .91 \\
\hline
\end{tabular}

Note. Descriptives were calculated using Full Information Maximum Likelihood Estimation to account for missing data using Mplus. Self report measures all used a 7 point response scale ranging from 1 to 7 (all response options were used). Cronbach's alpha is listed on the diagonal for all applicable scales. 
SHORT-TERM MOTIVATION TRAJECTORIES

Table 2

Expectancy and Utility Value Unconditional Growth Parameter Estimates

\begin{tabular}{|c|c|c|c|c|c|c|c|c|c|}
\hline & & \multirow[b]{2}{*}{ Estimate } & \multirow[b]{2}{*}{ Variance } & \multicolumn{2}{|c|}{$\begin{array}{c}95 \% \text { Plausible } \\
\text { value Range }\end{array}$} & \multicolumn{4}{|c|}{ Correlations } \\
\hline & & & & $\begin{array}{l}\text { Lower } \\
\text { Bound }\end{array}$ & $\begin{array}{l}\text { Upper } \\
\text { Bound }\end{array}$ & 1 & 2 & 3 & 4 \\
\hline 1 & $\begin{array}{l}\text { Expectancy } \\
\text { Intercept }\end{array}$ & $5.44 *$ & $0.47 *$ & 4.08 & 6.84 & & & & \\
\hline 2 & Expectancy Slope & $-0.31 *$ & $0.27 *$ & -1.47 & 0.79 & 0.12 & & & \\
\hline 3 & $\begin{array}{l}\text { Utility value } \\
\text { Intercept }\end{array}$ & $4.97 *$ & $0.65^{*}$ & 3.40 & 6.54 & $0.52 *$ & -0.05 & & \\
\hline 4 & Utility value Slope & $-0.09 *$ & 0.08 & -0.69 & 0.49 & 0.06 & $0.83 *$ & 0.36 & \\
\hline
\end{tabular}


running head: SHORT-TERM MOTIVATION TRAJECTORIES

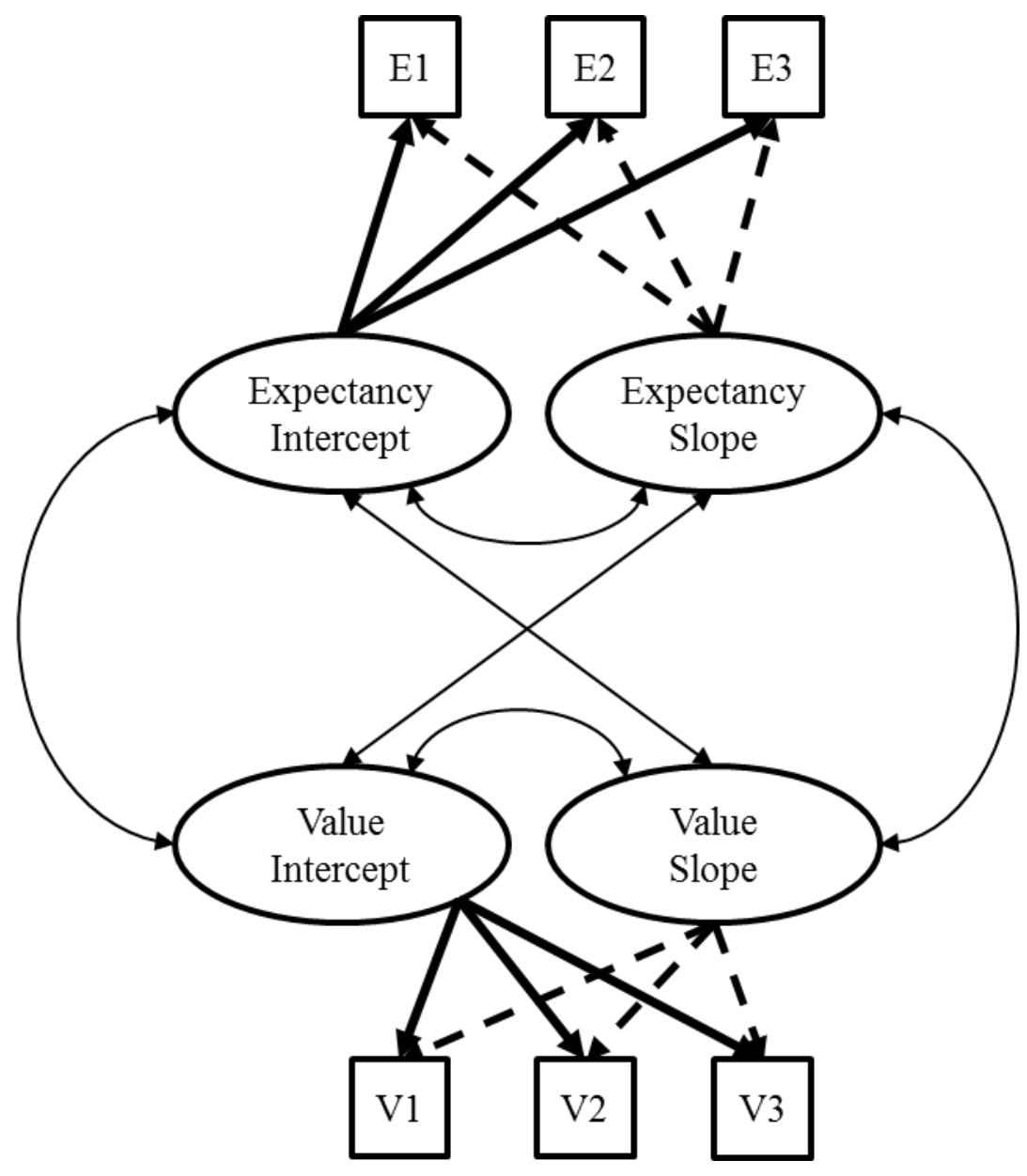

Figure 1 


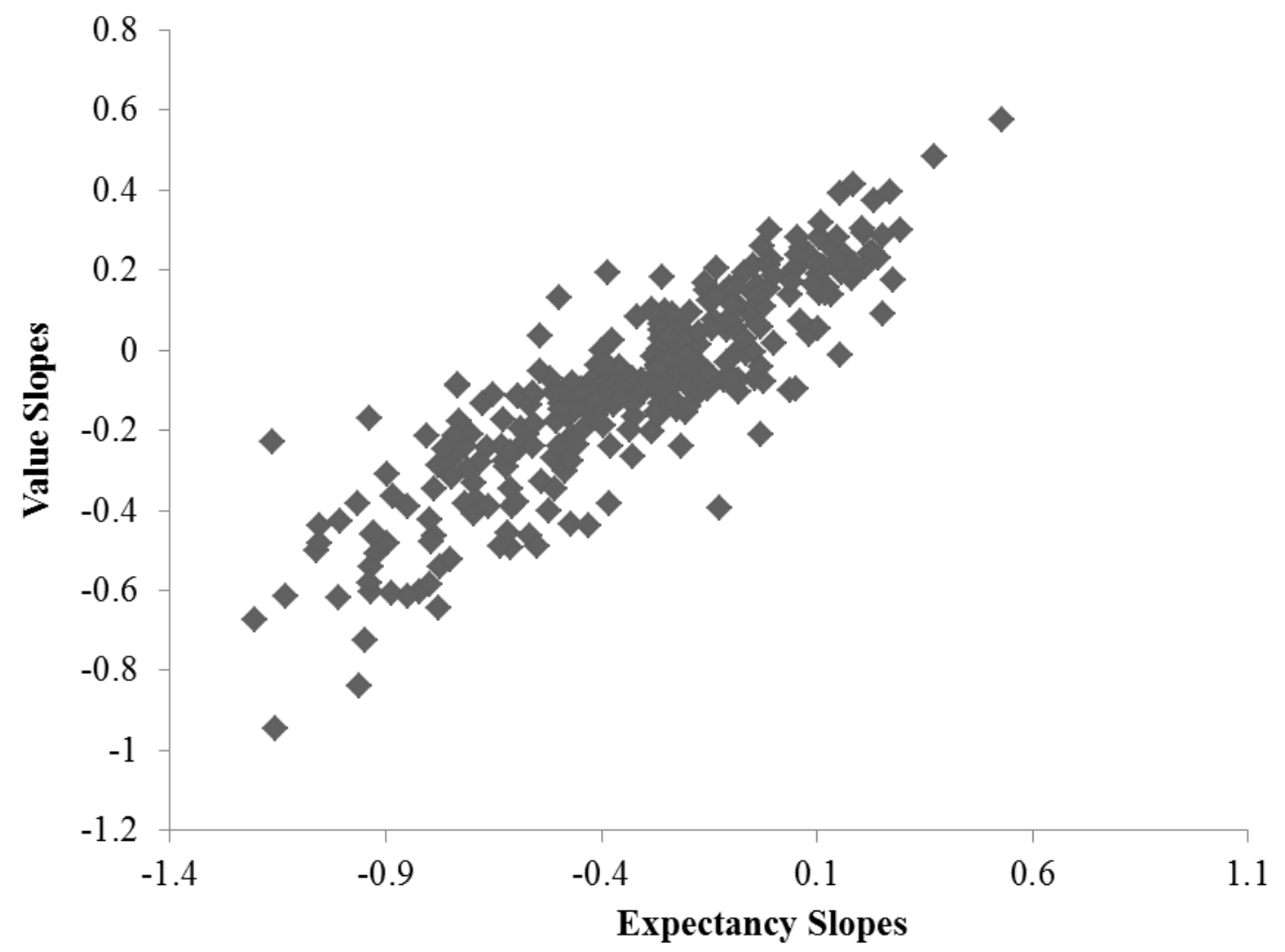

Figure 2 


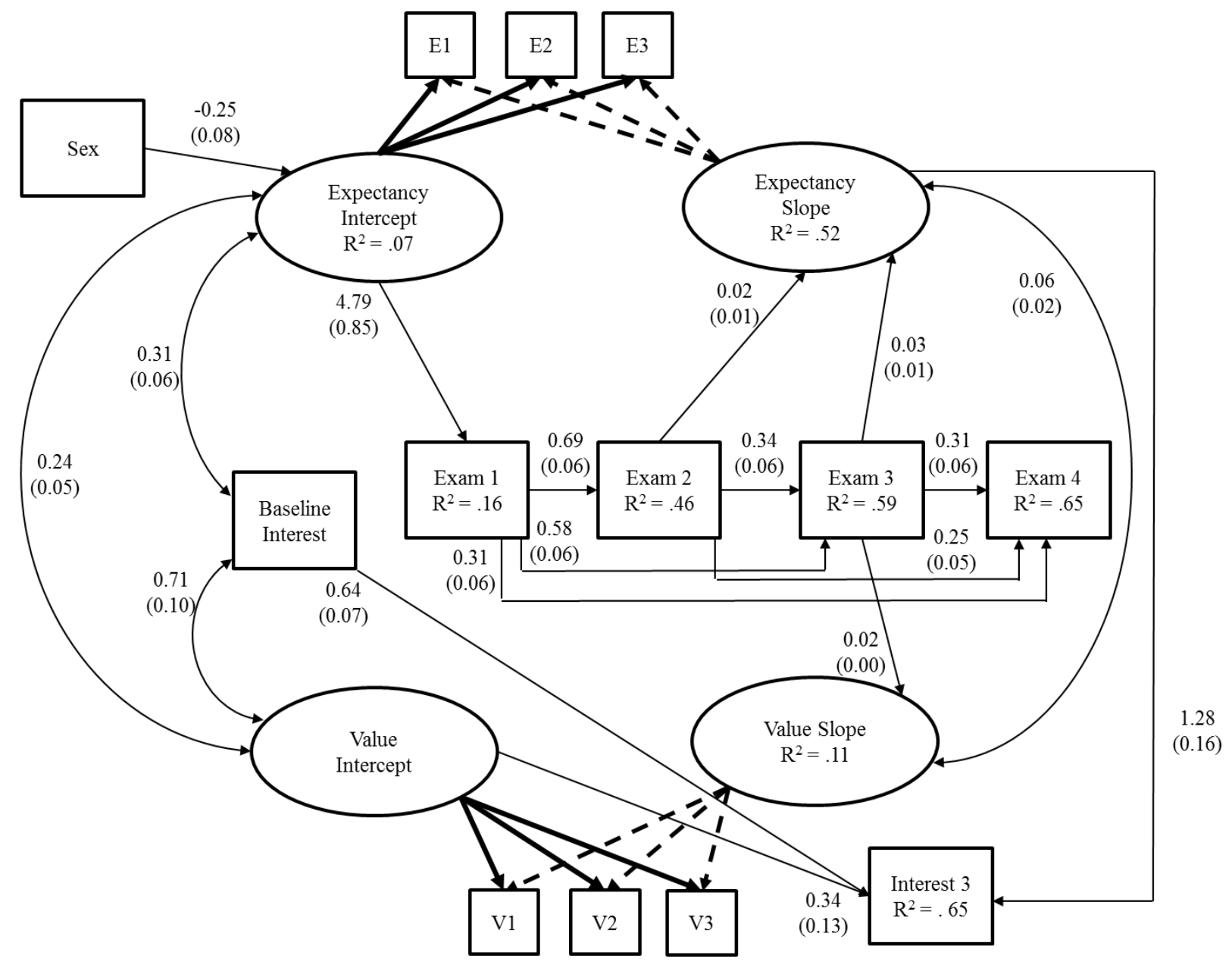

Figure 3 